\title{
Study of Grapevine Water State Improvement by Enhancing Quality of the Soil in the Vineyards of Castellon Region (Spain)
}

\author{
L. Shkarupilo ${ }^{1}$, M. Malafosse ${ }^{2}$, D. Soriano ${ }^{3}$, J.L. Aleixandre-Tudó ${ }^{1}$, J. Giner ${ }^{3}$, J.L. Aleixandre ${ }^{1}$ \\ ${ }^{1}$ Instituto de Ingeniería de Alimentos para el Desarrollo, UniversitatPolitècnica de València, Spain. \\ ${ }^{2}$ Bodega Barón d’Alba, Les Useres, Castellón (Spain) \\ ${ }^{3}$ Departamento de Produción Vegetal, UniversitatPolitècnica de Valencia, Spain
}

*Corresponding Author: Jose Luis Aleixandre, Instituto de Ingeniería de Alimentos para el Desarrollo, UniversitatPolitècnica de València, Spain.

\begin{abstract}
This work is about the improvement of the grapevine water state under Mediterranean climate conditions regarding projections of the increasing temperatures and a threat of the soil desertification, via enhancing the soil quality and "biological soil fertility" in particular, by appliance of the different viticultural techniques. The methods and technics used were: ramial chipped wood $(R C W)$, combination of the $R C W$ and beans as a cover crop, control plot, cultivated and without cover crop. Following water state of the plant by analyses of predawn leaf water potential and stem leaf water potential. The results obtained were the following: water state of the plant was better where the techniques were applied. Soil respiration and fauna showed higher results in the modalities with the applied techniques, than in the conventional cultivation modality, cover crop consumed the water in the nether soil horizon hence forcing vine to explore deeper horizons for the water uptake. In the third sample, modality covered with RCW contained soil aggregates. Modality with $R C W$ did not create lack of nitrogen for the vine plant and demonstrated the highest soil humidity among the modalities. The conclusions of the study stated that technics as $R C W$ and cover cropping are able to activate soil fauna, which improves soil structure and contributes into increase of the soil organic matter. Comparing to the cultivated soil, enhanced soils where techniques were applied, positively affect the water state of the vine plant and decreases its stress under the hot Mediterranean climate.
\end{abstract}

Key words: vine water state, soil quality, Mediterranean climate, $R C W$, cover cropping, soil fauna, organic matter.

\section{INTRODUCTION}

Climate change projections give evidence for significant changes in both the growing season temperatures and precipitations in the next decades. Particularly in southern Spain, the excessive warming projected for the end of the twenty-first century would impede the production of highquality wine and would hinder grapevine growth (Fraga et al., 2013, Fraga 2014).

As mentioned by Jones (2007), everything depends on where a region is today in terms of climate and the magnitude and rate of the future warming. We will examine mesoclimate of the area, where Bodega Baron d'Alba, the sponsor of this study, is located. We will also try to analyse the consequences of this climate on the vineyard.

Bodega Baron d'Alba is nfluenced by the local steppe climate. There is a little rainfall throughout the year. As it was previously noteced climate in this area is considered to be BSk according to the Köppen-Geiger climate classification. The average temperature in Castellón de la Plana is $17.0^{\circ} \mathrm{C}$. The rainfall here averages $434 \mathrm{~mm}$ (Climate-Data Organization, 2016; European Comission, 2016, PNACC, 2006).

Regarding in the details climate characteristics of the current study area, we will use data from meteoblue.com. The meteoblue climate diagrams are based on 30 years of hourly weather model simulations. They give good indications of typical climate patterns and expected conditions such as temperature, precipitation, sunshine and wind (Meteoblue,2016). The "mean daily maximum" (solid 
red line) shows the maximum temperature of an average day for every month for Les Useres (Castellón, Spain).

It is important to notice the presence of certain microclimate in the area. Pla de les Useres is located at the foot of the Peñagolosa massif from where air currents go down and cool summer nights. Can observe this effect from Figure 3, when summer night temperature can reach $14^{\circ} \mathrm{C}$ in June, $17^{\circ} \mathrm{C}$ in July and $18^{\circ} \mathrm{C}$ in August thereby creating a gap over $10^{\circ} \mathrm{C}$ which is preferable for the conservation of aroma compounds and balance of natural acids in the grape.

Concerning soils, as reported by Ministry of Agriculture, Food and Environment of Spain, based on lithological and hydrological characteristics, geological formations in Castellon and Valencia are zones formed by loose or semi consolidated materials, such as gravel, sand and silt that cover the valley bottoms of major rivers (Soils, 2016).Soil is deep, allowing good development of root system in the vineyards.

The aim of the study was to improve soil structure and enhance soil micro porosity. Activate soil fauna, which will create aggregate structure, thus increase aeration, facilitate roots penetration and rise water-holding capacity of the soil. Introduce no-tillage techniques in order to decrease the effect of soil erosion and degradation of organic matter, caused by cultivation.

\section{Materials ANd Methods}

The experiment was realized in the vineyards of Bodega Baron d'Alba (2016), Geographical Indication Vinsde la Terra de Castelló (Spain). Three different modalities were implemented into three plots, $180 \mathrm{~m}^{2}$ each. Grape variety is Merlot, planted in the year 2003 on the SO4 rootstock and with density $2.6 \times 1.2 \mathrm{~m}$.

Soil texture is considered as sedimentary originated. It is determined as sandy loam (53\% of sand, $36 \%$ of lime, $11 \%$ of clay), with a limestone as a parent rock. Soil is deep, allowing good development of root system in the vineyards.

First modality, named "plot A" was the combination of green manure between rows and ramial chipped wood (RCW) under the row. On the second, named "plot B", RCW was spread over the entire soil surface, $4 \mathrm{~cm}$ thickness between the rows and $10 \mathrm{~cm}$ thickness under the row. "Plot T" was a control modality, plowed and without any cover crop.

Spreading of the CRW was carried out the $15^{\text {th }}$ of December 2015. Green manure (field beans) for the plot A was sown on $1^{\text {st }}$ of December 2015. Cover crops rows were $2.0 \mathrm{~m}$ wide. Cover crops were mowed on $11^{\text {th }}$ of April 2016, with the height of 40-50 cm while flowering and later destroyed by surface tillage on $25^{\text {th }}$ of April was destroyed. First, to decrease water competition for the vine, second, to create their decomposition, so the input of nitrogen. Plot $T$ was ploughed on the $1^{\text {st }}$ of December and $15^{\text {th }}$ of April 2016.

During this study, several samplings were undertaken: soil sampling for various physical and chemical analyses; leaves sampling for the information about nutrition of the plants; sampling of the earthworms. Water state of the grape plants was studied by measuring predawn leaf water potential and stems water potential.

One of the plots was totally covered with RCW, which consisted of the shredded branches of Platanus, the leftovers of the pruning, provided by the Municipality. Second plot consisted from both, RCW and cover cropping. For this purpose, field beans were chosen.

Taking of the samples were conducted under the protocols and methodology recognised internationally, (eg. "Prélèvement des Lombriciens", developed by Université de Rennes1, Tullgren method of the arthropod extraction etc.).

Methodologies used in the laboratory analyses were also internationally validated $\left(\mathrm{pH} \mathrm{H}_{2} \mathrm{O}\right.$; organic matter determination by Walkeyand Black method (1934).

\subsection{Soil Sampling and Measurements}

Sampling of a soil is a complex problem that deserves detailed consideration. Needless to say, that the details of procedure should be determined depending on the purpose of the sampling. Sampling 
should take into account variations of the soil according to the profile's depth and area of land, taking also in consideration whether there are type units of natural soils, orelse of practical units, referred to a field or farm unit. The majority of the existed methods of the soil analysis depend if the samples are representative and if operations of managing are proper (Sancho et al., 2001).

In current study the systematic soil sampling was conducted, where each unit is selected at regular distances from the rest (equidistant parallel and orthogonal lines).

Soil was sampled with a cylinder of $0.3 \mathrm{~cm}^{3}$ within help of a hammer and a hoe. Samples were taken from two horizons $0-20 \mathrm{~cm}$ (horizon 1) and $20-40 \mathrm{~cm}$ (horizon 2) from six points of each plot, four between the rows and two under. Soil from each sample was collected into separate plastic bag numerated accordingly $1.1 ; 1.2 ; 2.1 ; 2.2 ; 3.1 ; 3.2 ; 4.1 ; 4.2 ; 5.1 ; 5.2 ; 6.1 ; 6.2$, where the first character corresponds to the sample number and second corresponds to the soil horizon). Each title contained a letter of the modality corresponded as A, B and T (ex. A1.1, A1.2, etc.). In order to have enough soil for all analyses needed, each sample was doubled. Soil was sampled three times during period of current study: $4^{\text {th }}$ of March, $25^{\text {th }}$ of April and $20^{\text {th }}$ of June.

Once soil samples were delivered to the laboratory, they were preliminary conditioned for subsequent different physical and chemical analyses. Samples were placed on trays and lumps were disaggregated by hands. Trays stayed on the air $\left(25^{\circ} \mathrm{C}\right)$ until the humidity of the soil equilibrated with the humidity of the laboratory. Dusting is an indication of having achieved this balance. Samples after were sifted on a sieve with a mesh size of $2 \mathrm{~mm}$. The portion that has passed through the sieve was collected into container. This fraction is called air- dry fine soil and was used for the following analyses (Sancho et al., 2001).

Soil $\mathrm{pH}$ is a measure of its acidity or alkalinity and is an important property because of its influence on the supply of nutrients (cations and anions) to plants, the chemical behaviour of toxic elements and the activity of microorganisms(Proffitt, 2014).

Soil acidity is associated with the presence or relative quantity of acid and base cations in exchange sites of the micelle, using this term to describe a solid loaded particle, either clay or organic nature, which is considered as a part of the acid- base- salt system of the soil. Intensity of the acidity is commonly characterized by measuring the hydrogen ion activity and expressed as $\mathrm{pH}$.

The measurement of the electrical potential that creates in the glass membrane of the electrode is the function of the activity of hydrogen ions at both sides of the membrane, by reference a calomel electrode with a salt bridge.

Electrical conductivity is used as a measure of saline concentration in water (ECw) and saturated soil paste (ECe) and is expressed as $\mathrm{dS} / \mathrm{m}$. Sodium ions are particularly important as they drastically affect soil characteristics and the absorptive capacity of the plant root system. The ESP (exchangeable sodium percentage) index is the ratio between sodium ions and the total cation exchange capacity (Geeson et al., 2002).

The determination of the electrical conductivity normally uses to indicate total concentration of the ionized components in solutions. Soluble salts in the soil determine the presence of a series of cation combinations: calcium, magnesium, sodium, potassium and anions: carbonates, bicarbonates, chlorides, sulfates etc. The conductivity value is related to the sum of cations (or anions) and generally correlates with total dissolved solids. Water that contains dissolved salts of the type normally found in soil, conduct electrical current approximately in proportion to the amount of dissolved salt. Therefore, the measure of the conductivity provides with the information about total concentration of ionized components. The determination of the electrical conductivity of a solution realizes measuring of the electrical resistance between two parallel-submerged electrodes in the solution (Soriano et al., 2001).

Determination of soil humidity provides the information about water absorbed by soil at the expense of atmospheric humidity. Corresponds to the hygroscopic water that forms a thin film around soil particles and retains by them energetically, and is not absorbable by the plant roots. Hygroscopic water is eliminated by heating sample in the oven at $105^{\circ} \mathrm{C}$.

The content of soil organic carbon can be expressed directly as a percentage of carbon or can be calculated in the form of organic matter by multiplication by the conventional factor. This 
conventional factor $(1,724)$ passes from organic carbon to organic matter. It is based on the hypothesis that soil organic matter contains $58 \%$ of carbon (Soriano et al., 2001).

Soil respiration is considered to be a good estimator of overall biological activity and has been proposed as a descriptor of soil quality. Soil respiration measurements are increasingly used in studies of soil carbon cycling to detect early changes in decomposition rate of soil organic matter in response to various soils or crop management practices (Rochette et al., 2005).

Organic matter in soil is the most important fraction that supports microbial populations, especially the biologically available portion of soil organic matter. Microbial biomass, the living component of soil organic matter, constitutes $2-7 \%$ of the organic carbon in soils. Microbial biomass acts as the engine for organic matter turnover and nutrient release (Lines-Kelly, 2004).

To measure microbial respiration (soil respiration) chamber method described by Anderson was used. Author defined soil respiration as oxygen uptake or carbon dioxide evolution by bacteria, fungi, algae and protozoan, and includes the gas exchange of aerobic and anaerobic metabolism (Anderson, 1982).

The decomposition of soil organic matter is measured by incubating soil samples in closed containers (daily aerated for one minute to avoid oxygen deficiency). The $\mathrm{CO}_{2}$ produced by the metabolic activity of soil microorganisms is measured using a trap of soda, consisting of a solution of $\mathrm{NaOH}$ with a known initial concentration.

Soda is added with excess. When the experiment ends all the carbonate produced precipitates by adding $\mathrm{BaCl}_{2}$ and soda that has not been neutralized by the respiration of microorganisms is measured with $\mathrm{HCl}$.

In the size spectrum of soil fauna, the mites and collembolans are found among the mesofauna. Members of the micro arthropod group are unique, not so much by their body size as by the methods used for sampling them. Micro arthropods are too small and numerous to be sampled as individuals. Instead, small pieces of habitat (soil, leaf litter, or similar materials) are collected and the micro arthropods extracted from them in the laboratory (Coleman, 2004).

A modified Tullgren apparatus, based on the Berlese funnel (thus often called Berlese-Tullgren funnel), and its various modifications, is the most commonly used method for separating arthropods from soil and litter. The essential component of these extractors is a sample container with wire mesh or screening on the bottom, a metal or plastic funnel in which, or over which, the sample container is placed and a collecting vessel below the funnel which usually contains a liquid preservative, generally $80 \%$ ethanol. A source of heat and desiccation (light bulb) is placed above the sample. The objective is to create a steep gradient of temperature and moisture throughout the sample. Arthropods react to the heat and desiccation by moving downward (away from the heat) and eventually fall through the screen at the funnel bottom into the preservative. Cheesecloth below the sample and/or a baffle in the funnel is necessary to reduce debris from the sample falling into the preservative as the sample dries out, or is agitated by the movement of larger organisms (Winchester, 1999).

\subsection{Sampling of the Earthworms}

It was conducted on the 28th of April, following the protocol designed by the University of Rennes 1 , France (Poupelin et al., 2016).

\subsection{Water Status of the Plant}

To determine the influence of environmental and cultural conditions on vine water status, a sensitive physiological indicator that integrates both, soil and climatic conditions, is required. The pressure chamber (Scholander) is a reliable method for determining the water status of field-grown vines. Pressure chamber measurements can provide values of dawn leaf water potential (dawn $\Psi$ ), daily leaf water potential (leaf $\Psi$ ) and stem water potential (stem $\Psi$ ) (Chonea, 2001).

For the monitoring water status of the vine plants in current study measurements of predawn leaf water potential (predawn $\Psi$ ) and stem water potential (stem $\Psi$ ) were selected.

Predawn leaf water potential measures plant water status at zero plant water flux and provide information on the root zone soil water potential because predawn plant water status is considered to 
be in equilibrium with soil water status. Daily stem $\Psi$ is the result of whole plant transpiration, and soil and root/soil hydraulic conductivity (Chonea, 2001).

As reported in methodology designed by "InstitutFrançais de la Vigneet du Vin", four points are needed to characterize the water state of the plant during the growing season.

Consequently, for each time of the measurements predawn $\Psi$ and stem $\Psi$ were conducted in the same day for the highest accuracy possible and in the relatively similar weather conditions within 2-3 weeks interval. Water state was analysed at five points of studied period: 20th of May, 4th of June, 21th of June, 8th of July, 26th of July. The measurements of the season were undertaken on the same plants.

For both, predawn $\Psi$ and stem $\Psi$, measurements were conducted on a sample of five healthy leaves by modality, that are chosen on the shaded side of primary branch, in the early afternoon, from five marked plants with identical vegetative expressions, unharmed by wood diseases. To avoid the "edge effects", plants were selected from the middle part of the basic plot. Predawn $\Psi$ and stem $\Psi$ are measured with a pressure chamber provided with a compressed nitrogen source with a flow regulator and a precision manometer $(0.001 \mathrm{MPa})$. Water potential notes when moisture appears on the section of the woody beams of the petiole. This value corresponds to the pressure of the chamber shown by the manometer, in absolute value.

\subsection{Predawn Leaf Water Potential}

Predawn leaf water potential refers to a plant when all the stomata are closed and it represents the availability of water in the environment. The measurement is done before the sunrise. This is a strong indicator that allows obtaining solid thresholds of the reference, validated internationally. In end of the night, while transpiration is negligible and the plant has replenished its water reserves, the tension sap in the plant is considered to be in equilibrium with the soil water potential in the root installation zone.

There is a low variation between the leaves. This method is suitable for the vineyards with the high water stress, typically Mediterranean, since leaf water potential is not too sensitive to low stresses.

The measurement takes place in the end of the night before the sunrise (from 2a.m. until dawn) with no precipitation occurred in the previous four days. Weather conditions at the time of measurement must be constant from one sampling to another (wind, humidity).

Leaf, dry and intact, was taken just before the measurement by breaking the petiole at its insertion on the node (it is not possible to pick the leaves in advance and store them). The petiole was cut off with a sharp cutter to avoid crushing of the tissue. It was then introduced into the cover opening, that seals the petiole, and then leaf was placed in the chamber.

The value of predawn leaf water potential is the average of the measurements on the determined modality.

Thresholds: $0.2 \mathrm{MPa}<$ predawn $\Psi$ no water stress;

$0.3 \mathrm{MPa}<$ predawn $\Psi<-0.2 \mathrm{MPa}$ low water stress;

$0.5 \mathrm{MPa}<$ predawn $\Psi<-0.3 \mathrm{MPa}$ low to moderate water stress;

$0.8 \mathrm{MPa}<$ predawn $\Psi<-0.5 \mathrm{MPa}$ moderate to severe water stress;

Predawn $\Psi<-0.8 \mathrm{MPa}$ severe water stress.

(InstituteFrançais de la Vigne et du Vin, 2016)

\subsection{Stem Water Potential}

The stem water potential is measured during the day, while photosynthesis is active and the climatic demand is significant. It proceeds on a sample of the leaf, previously wrapped in a plastic, covered with aluminium foil. Bagging prevents leaf transpiration, so leaf water potential equals stem water potential that represents the water status of the entire plant. Stem water potential reports to the ability of the plant to conduct water from soil to atmosphere, it provides reliable information on the water status of the plant in conditions of transpiration, and appears to account very satisfactorily the 
available water in the soil. This data is close to data provided by the predawn leaf water potential, however with increased resolution at moderate water deficits.

The chamber is pressurized very gradually (the accuracy of the measurement is very dependent on the pressure rise rate). An increment of 0.002 (beginning of the season, no stress) to $0.004 \mathrm{MPa}$ (late season, stress exhausted) is recommended.

\subsection{Measurement}

Leaves were bagged two hours before the measurement from the shaded side of the row to avoid overheating during the bagging period. Measurement took places around a solar noon, which means 14.00 in Spain in the summer, under the constant weather conditions (clear and sunny, wind limited) and with no precipitation occurred in the previous four days.

Leaf in its bag was taken just before the measurement by breaking the petiole at its insertion on the node (it is not possible to pick the leaves in advance and store them). The petiole was cut off with a sharp cutter to avoid crushing of the tissue. It was then introduced into the cover opening, that seals the petiole, and then leaf was placed in the chamber.

The value of stem leaf water potential is the average of the measurements on the determined modality.

\subsubsection{Thresholds}

$0.6 \mathrm{MPa}<$ stem $\Psi$ no water stress

$0.9 \mathrm{MPa}<$ stem $\Psi<-0.6 \mathrm{MPa}$ low water stress;

$1.1 \mathrm{MPa}<$ stem $\Psi<-0.9 \mathrm{MPa}$ low to moderate water stress

1.4 MPa <stem $\Psi<-1.1 \mathrm{MPa}$ moderate to severe water stress;

Stem $\Psi<-1.4 \mathrm{MPa}$ severe water stress.

(Institut Français de la Vigne et du Vin, 2016)

\subsection{Mineral Content of the Leaves (Foliar Analyses)}

In order to study the incidence of different culture itineraries on vines nutrition, the foliar analyses were carried out at thevéraisonmoment. Eight leaves per plant were collected: entire, with the petiole, opposite to the primary cluster. Leaves were collected from four plants per sample, three samples per modality. Foliar analysis itself was conducted in the same day in the laboratory KUDAM, Alicante, on $26^{\text {th }}$ of July.

As a statistical method of analyses, PSPP software was chosen. Massive of data was tested on normality, homogeneity and according to the outputs, parametric or non-parametric test was conducted (ANOVA or KRUSKAL-WALLIS, as three modalities were compared each time).

\section{RESULTS AND DiSCUSSION}

\subsection{Soil Fertility}

In accordance to the obtained results, $\mathrm{pH}$ of the soil in all modalities is in the suitable frames between 5.5 and 8.5 (The Australian Wine Research Institute, 2010).

According to the review, published by the Perth Region Natural Resource Management (Australian Governmental Program), salinity in sandy loam soil $<0.25 \mathrm{dS} / \mathrm{m}$ considered to be non-saline. All modalities correspond to this definition (Proffitt, 2014).

Water retention capacity did not vary too much between the modalities and within the season. Average values are demonstrated in Table 1.

Table1: .pH, salinity and water retention capacity, based on the obtained results

\begin{tabular}{|l|l|l|l|}
\hline Modality & \multicolumn{1}{|c|}{$\mathrm{pH}$} & \multicolumn{1}{|c|}{ Salinity, $\mathrm{dS} / \mathrm{m}$} & \multicolumn{1}{|c|}{ Water retention capacity, mm water/mm soil. } \\
\hline A & 8.34 & 0.23 & 0.14 \\
\hline B & 8.11 & 0.23 & 0.15 \\
\hline T & 8.41 & 0.17 & 0.15 \\
\hline
\end{tabular}


Study of Grapevine Water State Improvement by Enhancing Quality of the Soil in the Vineyards of Castellon Region (Spain)

\subsection{Organic Matter}

Table2: Interpreting soil organic carbon (OC) results in relation to soil condition/quality, (Proffitt, 2014).

\begin{tabular}{|l|l|l|}
\hline \multicolumn{1}{|c|}{ OC rating } & \multicolumn{1}{|c|}{ Level of OC \% } & \multicolumn{1}{c|}{ Effect on soil condition/ quality } \\
\hline Low & $0.4-1.0$ & Poor structural condition and stability \\
\hline Moderate & $1.0-1.8$ & $\begin{array}{l}\text { Moderate structural stability, condition, pH buffering, nutrient levels, } \\
\text { water holding capacity }\end{array}$ \\
\hline High & $1.8-3.0$ & $\begin{array}{l}\text { Good structural condition and stability, high pH buffering capacity, } \\
\text { high nutrient levels, high water holding capacity }\end{array}$ \\
\hline Very high & $>3.0$ & $\begin{array}{l}\text { Dark colour, large amount of organic material, soil often associated } \\
\text { with undisturbed woodland/forested areas }\end{array}$ \\
\hline
\end{tabular}

Respectively to this table (Table 2), we can observe the evolution in OC inside the modalities, between them and their horizon in the table, which contains obtained in the current study results (Table 3).

Table3: Results of soil organic carbon (\%).

\begin{tabular}{|c|c|c|c|c|c|c|c|c|c|}
\hline & \multicolumn{3}{|c|}{ Modality A } & \multicolumn{3}{c|}{ Modality B } & \multicolumn{3}{c|}{ Modality T } \\
\hline Sampling & 1 & 2 & 3 & 1 & 2 & 3 & 1 & 2 & 3 \\
\hline Horizon 0-20cm & 0,52 & 0.87 & 1.12 & 0.68 & 1.22 & 1.07 & 0.5 & 0.72 & 0.74 \\
\hline Horizon 20-40cm & 0.26 & 0.5 & 0.74 & 0.26 & 0.65 & 0.73 & 0.34 & 0.9 & 0.8 \\
\hline
\end{tabular}

Initial quantity of $\mathrm{OC}$ was almost the same in the upper horizon of the modalities $\mathrm{A}$ and $\mathrm{T}$. In modality B it was higher. It can be possibly explained by higher microbial activity in the soil under RCW that was spread over its surface in December. General positive evolution is observable in all horizons of each modality. Nonetheless, only in the upper horizons of modalities A and B quantity of soil OC, according to the Table 3, has changed from the category "Low: poor structural condition and stability" to the category "Moderate: moderate structural stability, condition, $\mathrm{pH}$ buffering, nutrient levels, water holding capacity". Low OC in the nether horizon is a normal phenomenon. However, it is noticeable that in the horizon $20-40 \mathrm{~cm}$ of the second and third samplings of the modality $\mathrm{T}$ there was more OC that in the upper horizon. Presumably, the reason is ploughing, that turns soil layers and incorporates weeds in the nether horizon.

The increase in organic matter content in the soil was among the goals of current study. In order to verify if aimed modalities achieved expected results, statistical test was conducted, where sums of the values for each horizon of each modality from three samplings undertaken were compared.

Significant difference in organic matter was observed in horizon $0-20 \mathrm{~cm}$ between modality $\mathrm{T}$ with $\mathrm{A}$ and B. Between modalities A and B difference was not significant. Highest percentage of organic matter belongs to modality $\mathrm{B}$, lowest to modality $\mathrm{T}$.

In the horizon $20-40 \mathrm{~cm}$ significant difference in organic matter was observed between modalities $\mathrm{A}$ and T. Between modalities B and A, B and T difference was not statistically significant. Horizon 2040 of modality $\mathrm{T}$ demonstrated the highest percentage of organic matter of the season, $\mathrm{A}$ had the lowest rate.

The evolution of organic matter content for each modality during the studied period was analysed statistically.

\subsection{Modality A}

The evolution in organic matter in the horizon $0-20 \mathrm{~cm}$ of modality A was observed in the beginning of studied period, between first and second samplings, but the evolution between second and third samplings was not statistically significant.

Statistical test demonstrated significant difference between first and third samplings of the horizon 20$40 \mathrm{~cm}$ for modality A, but between first and second, second and third samplings difference was not statistically significant. This can mean that organic matter content increased slowly during the studied period. 


\subsection{Modality B}

Statistically significant increase in organic matter of the horizon $0-20 \mathrm{cmof}$ modality B was identified in the beginning of studied period, between first and second samplings, from $1.27 \%$ to $2.07 \%$ accordingly. There was a decrease between second and third samplings, until $1.82 \%$, but it was not statistically significant.

In the horizon $20-40 \mathrm{~cm}$ there was significant difference between first and second samplings, growth from $0.54 \%$ to $1.11 \%$. Difference between second and third samplings is not significant with a slight rise up to $1.23 \%$.

\subsection{Modality $T$}

In the horizon $0-20$ of the modality $\mathrm{T}$ there was significant difference between first and third samplings with a rise from $0.9 \%$ to $1.27 \%$. Difference in-between first and second, second and third samplings were not significant.

In the horizon $20-40 \mathrm{~cm}$ the increase in organic matter was significant in the beginning of studied period, from $0.73 \%$ to $1.55 \%$ and a slight drop to $1.36 \%$ in the third sampling, but this drop was not statistically significant.

General tendency of evolution of organic matter and its difference between modalities along the studied period is present in the graph (Figure 1).

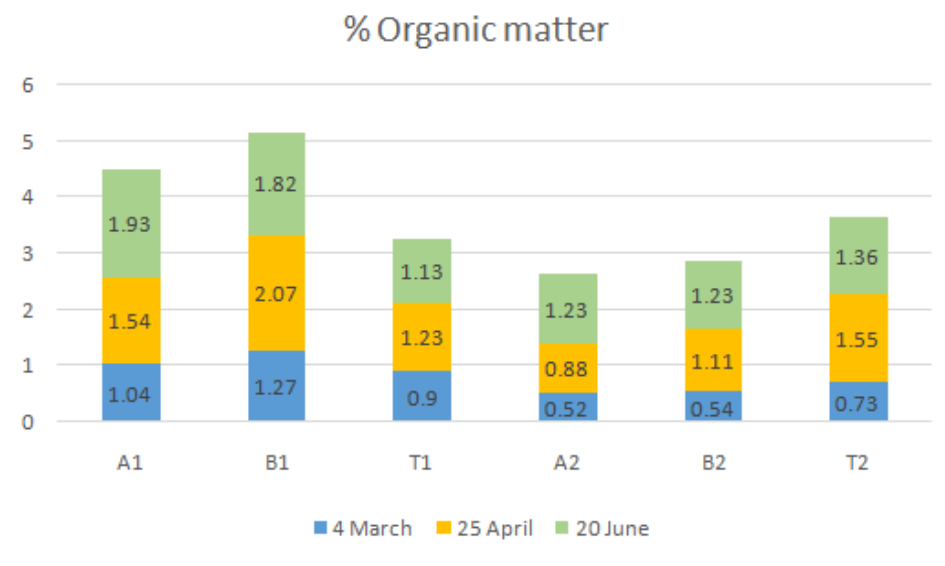

Figure1: Organic matter content (\%)

Comparing obtained values with data published by Perth Region Natural Resource Management, Australia (Proffitt, 2014) in sandy loam soils, which is our case, values inferior $1.2 \%$ considered to be low; $1.2 \%-2.4 \%$ moderate; superior 2.4 considered to be high.

As stated by Institute Français de la Vigneet du Vin (2016), in the vineyard soils, organic matter rates range from 0.5 to $2 \%$ even $2.5 \%$. There is no need to achieve too high amounts. The rate less than $1 \%$ can, however, be problematic.

Therefore, we can conclude, that positive tendency in upper horizon $(0-20 \mathrm{~cm})$ was achieved in modalities A and B. Modality A, which showed average 1.04\% on the moment of the first sampling, progressed from category "low" to "moderate" already in the second sampling with $1.54 \%$ and increased even more, up to 1.93 in the third sampling. Values of modality B, already from the first sampling $(1.27 \%)$, appeared to be in the category "moderate", what means, that at the moment of the first sampling, in the beginning of the March, OM content here was already higher than in the other modalities. The values of OM in modality B changed during the season with a rise up to $2.07 \%$ in the second sampling, and a slight decline to $1.82 \%$ in the third, but this decline, as it was previously mentioned, was not statistically significant. Modality $\mathrm{T}$ on the moment of the first sampling showed $0.9 \%$ ("low" organic matter category), which changed to "moderate" with $1.23 \%$ in the second sampling, and came back to "low" in the third with $1.13 \%$.

In the underneath horizon $(20-40 \mathrm{~cm})$, logical gradual increase in organic matter was observed in modalities A and B, where from the "low" category (in the first sampling $0.52 \%$ and $0.54 \%$ accordingly to the modalities; in the second $0.88 \%$ and $1.11 \%$ ) they changed to the "moderate" 
category in the third sampling with the same rate $1.23 \%$ in both modalities. The initial rate of $\mathrm{OM}$ in modality $\mathrm{T}(0.73 \%)$ was higher than in A and $\mathrm{B}$. In the second and third samplings values appeared to be in the "moderate" category with $1.55 \%$ in the second and $1.23 \%$ in the third sampling. This increase can be explained by the decomposition of the mown weeds after the ploughing on the $15^{\text {th }}$ of April, ten days before the second sampling.

Important to remember, that on the $25^{\text {th }}$ of April, after the samples were taken, cover crop of the modality A was destroyed by surface tillage in order to bring additional organic matter into the soil. This can explain why in the third sampling modality A showed that the highest organic matter content. This also proves the beneficial property of cover cropping in increase of organic matter content in the soil.

\subsection{Nitrogen and Other Minerals of the Vine Leaves}

As we can see from the Table 7 , the highest $\%$ of the nitrogen was present in the leaves of the modality B (1.87\%), following by $\mathrm{T}(1.81)$ and a (1.71). All these values correspond to the category of high content. Table also shows that effect of applying RCW in modality B did not provoke the lack of nitrogen for the vine plants. On the contrary, presumable effect of compensating missing nitrogen by planting leguminous (beans) as a cover crop was not demonstrated. From the bibliographical sources we know, that any stress that reduces plant activity will reduce nitrogen fixation (Lindemann and Glover, 2003 and 2008). Probably, drought, as a consequence of the low precipitations, appeared to stress leguminous plants and ceased one of its beneficial inputs.

Table4: Interpretation of vine tissue results, based on "Managing grapevine nutrition and vineyard soil health".

\begin{tabular}{|l|l|l|l|l|l|l|l|}
\hline Nutrient (\%) & Deficient & Marginal & Adequate & High & Modality A & Modality B & Modality T \\
\hline Nitrogen & $<0.7$ & & $0.8-1.1$ & $>1.2$ & 1.71 & 1.87 & 1.81 \\
\hline Phosphorus & $<0.15$ & $0.15-0.24$ & $0.25-0.50$ & $>0.50$ & 0.27 & 0.36 & 0.17 \\
\hline Potassium & $<1.0$ & $1.0-1.3$ & $1.3-3.0$ & $>3.0$ & 0.81 & 0.98 & 0.68 \\
\hline Calcium & $<1.0$ & & $1.2-2.5$ & & 3.87 & 3.51 & 3.96 \\
\hline Magnesium & $<0.30$ & $0.30-0.39$ & $>0.40$ & & 0.28 & 0.24 & 0.38 \\
\hline
\end{tabular}

As for other minerals their consideration was not among the objectives of current study. Therefore, we can reference them to the standards, but we are not able to discuss.

\subsection{Respiration}

Respiration rate of the soil was compared between modalities, as sums of the whole season, and in each sampling taken, inside the horizons $0-20 \mathrm{~cm}$ and $20-40 \mathrm{~cm}$.

Rates of the microbial respiration expressed in $\mathrm{mg} \mathrm{C/g}$ of the dry soil. Letters represent code of modality: A-green manure between rows and RCW under the row.

B-RCW was spread over the entire soil surface

$\mathrm{T}$ - Control modality, ploughed and without any cover crop

Numbers 1 and 2 situated next to the letter signify horizon, 0-20 cm and 20-40 cm accordingly.

Numbering of soil samplings corresponds: 1) $4^{\text {th }}$ of March, 2) $25^{\text {th }}$ of April, 3) $20^{\text {th }}$ of May.

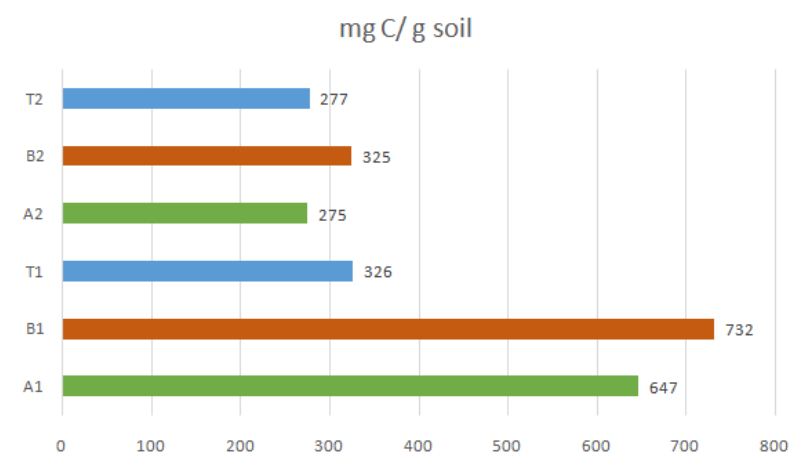

Figure2: Soil respiration, sums of the season 
Statistical test resulted, that rate of soil respiration in both horizons significantly differed between all modalities. Highest rates in both horizons showed modality B, that means that microbial activity in this modality was more than in A and T.

In the horizon $0-20 \mathrm{~cm}$ the highest value of the season, shown by the modality B was followed by modality A, while modality $\mathrm{T}$ had the lowest rate, approximately twice less than in A and $\mathrm{B}$. That means that microbial activity of the observed season in the upper horizon of the modalities A and B was almost twice higher that in $\mathrm{T}$ (Figure2). In the nether horizon there was significant difference through the season between modalities B with $\mathrm{A}$ and $\mathrm{T}$. between $\mathrm{A}$ and $\mathrm{T}$ sums of the values through the season did not show significant difference.

First sampling of the horizon $0-20 \mathrm{~cm}$ showed significant statistical difference between modalities. Highest respiration rate was observed in modality B, lowest - in modality $\mathrm{T}$. In modality a soil respiration rate was in between 2 modalities. In the horizon $20-40 \mathrm{~cm}$, first sampling showed that modalities $\mathrm{B}$ and $\mathrm{T}$ were not significantly different, but rate of respiration of modality $\mathrm{A}$ was significantly less (Figure 3).

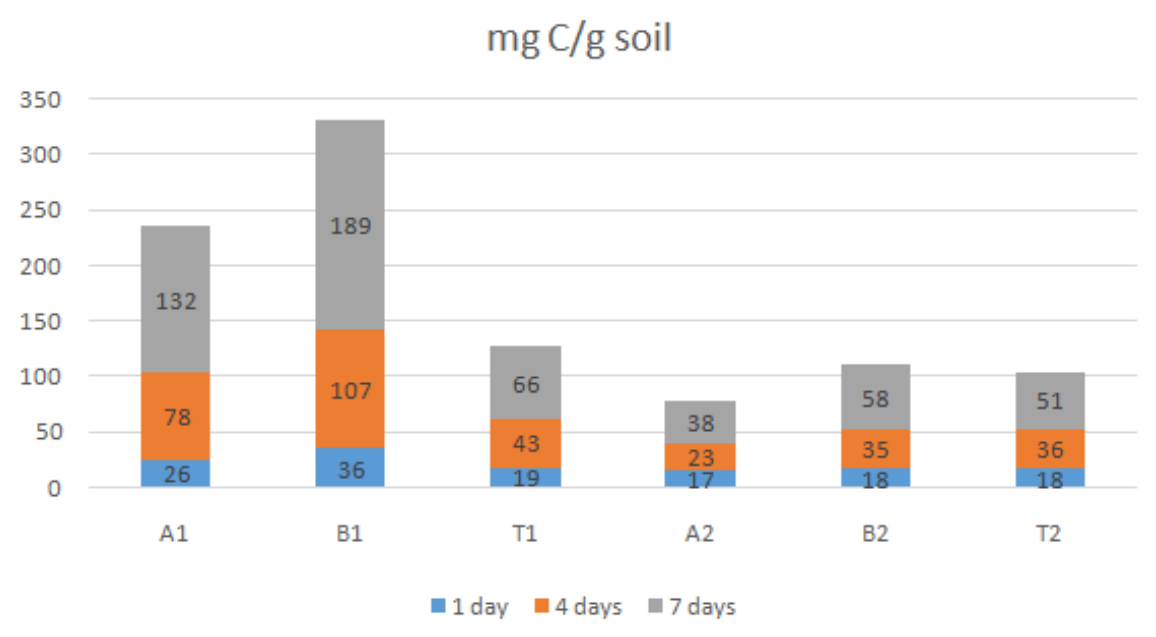

Figure3: Soil respiration of the first sampling, measured at the first, fourth and seventh day of the incubation.

In the second sampling (Figure 4) of the horizon $0-20 \mathrm{~cm}$ difference in soil respiration rates between modalities A and B was not significant, but $\mathrm{T}$ demonstrated the lowest value, almost half less than A and $\mathrm{B}$. This proves, that in modalities A and B microbial respiration was twice more active, than in $\mathrm{T}$. Second sampling of the horizon $20-40 \mathrm{~cm}$ demonstrated significant difference in rates of modalities $\mathrm{T}$ with A and B, T had the lowest values. Modalities A and B, did not differ significantly.

\section{$\mathrm{mg} \mathrm{C/g}$ soil}

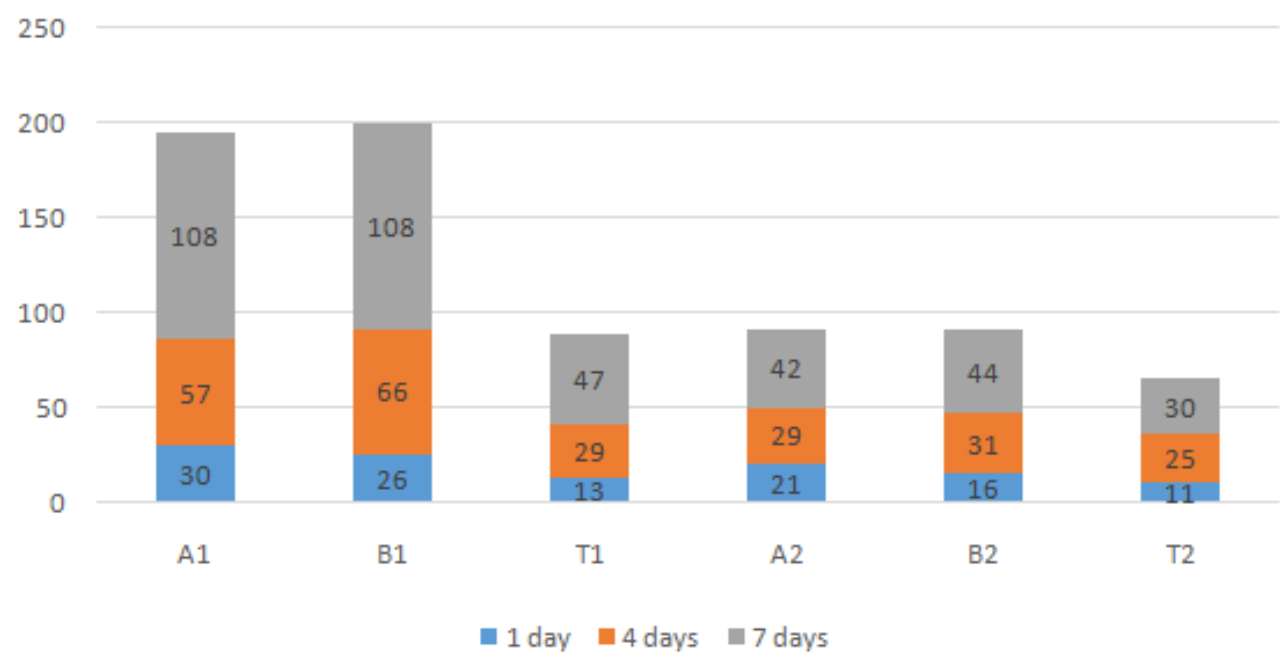

Figure4: Soil respiration of the second sampling, measured at the first, fourth and seventh day of the incubation. 


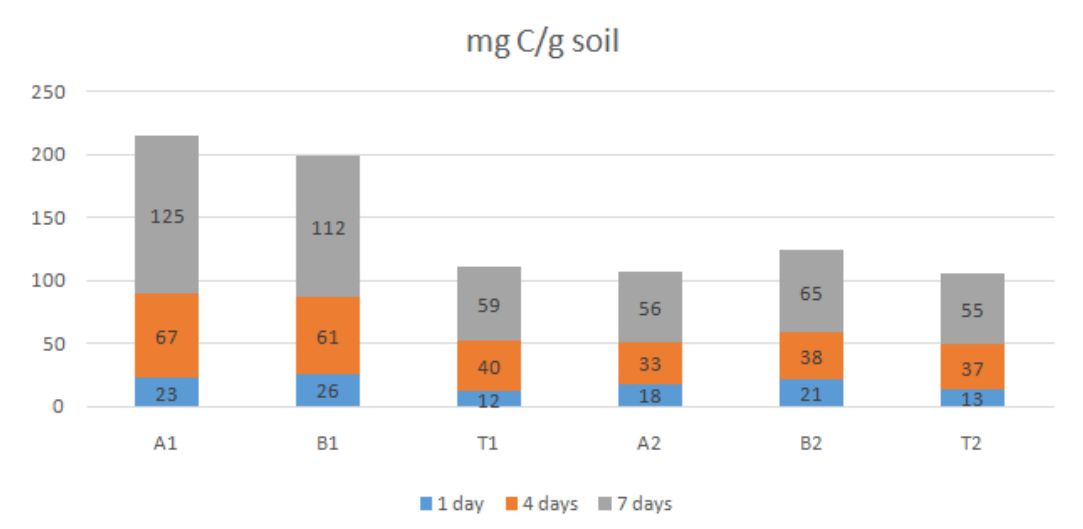

Figure5: Soil respiration of the third sampling, measured at the first, fourth and seventh day of the incubation.

In the third sampling (Figure5) of the horizon $0-20 \mathrm{~cm}$ there was significant difference between modalities, modality $\mathrm{T}$ demonstrated the lowest rates of soil respiration. In the horizon $20-40 \mathrm{~cm}$ modality $\mathrm{T}$ was significantly different from $\mathrm{A}$ and $\mathrm{B}$ and showed the lowest values.

Summarising the season, in the upper horizon soil respiration in modalities A and B was significantly higher than in $\mathrm{T}$. In the nether horizon, it was also higher in B, but between $\mathrm{A}$ and $\mathrm{T}$ difference through the season was not significant.

\subsection{Earthworms}

The extraction of the earthworms resulted poorly enough. Among three modalities, earthworms were found only in modality B, where soil was covered with RCW, and in a quantity of five individuals. According to the illustrated guide designed by the University of Rennes 1, France, these earthworms were distinguished as Epigeic earthworms. As it is stated by different authors (Arias et al., 2007b and 2008; Monroy et al., 2009 and 2011), Epigeic earthworms increase soil arthropod populations (especially Collembolas) during first steps of decomposition of organic matter. It is a characteristic feature of the initial stages of the earthworm-driven decomposition process. It is also known, that earthworms feed on protozoan bacteria, so we can assume their presence in modality B.

Occurrence of this food chain is observed when RCW is applied. This can explain why we did not find any earthworms in other modalities.

\subsection{Soil Fauna}

In this section, the results of Tullgren method of the extraction of the micro arthropods will be described. The quantity of the individuals is present in net values, which means a real number of the individuals found. It is done on purpose, because the aim was to compare modalities between themselves.

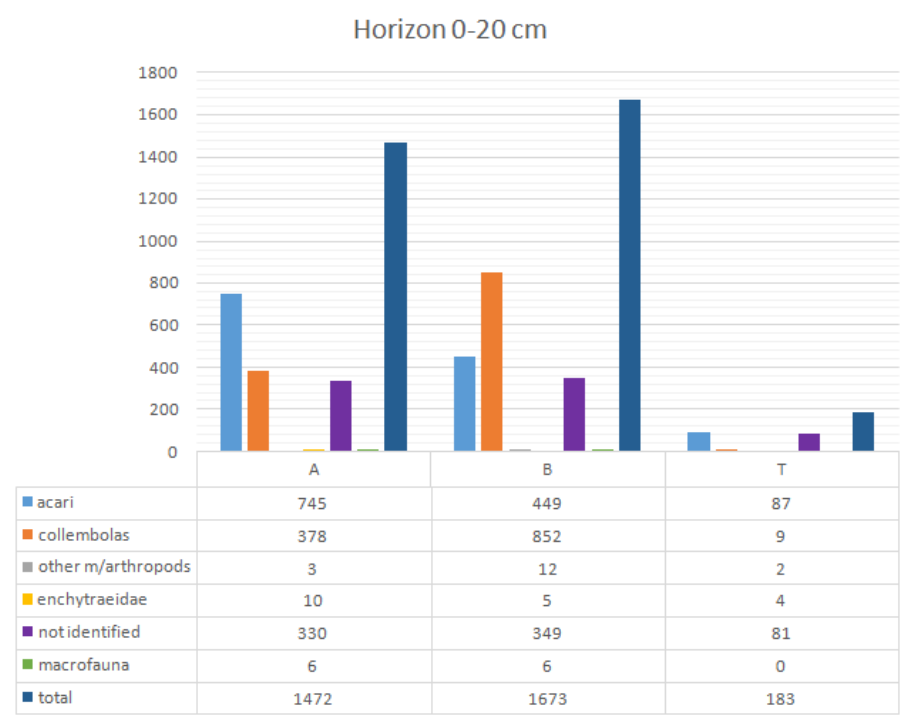

Figure6: Population rates between the modalities (March) 
The bar graph (Figure6) demonstrates differences between modalities in amount of individuals found in the soil samples (total and by subclasses). As we can observe, the richest soil life was in modality $\mathrm{B}$, where 1673 individuals were found. There were 200 individuals less in the modality A; and the least, 183 individuals only was found in modality T. It is remarkable, that in the upper soil level in modality A there are more acari, while in modality B collembolas are in abundance. Major part of identified individuals of modality $\mathrm{T}$ in its upper horizon are the acari.

It is stated, that half of the population found in the upper horizon of the modality A in the beginning of the March was represented by acari (mostly astigmatid and oribatid). Collembolas constitute 378 (26\%) individuals of the sample, 10 enchytraeidae found make $1 \%$ and the rest of the sample consisted from not identified individuals $(330(22 \%))$. There were also found four coleopteras with two other, not identified, representatives of the macro-fauna, but they do not make even $1 \%$ of the sample.

The collembolas composed half of the sample (852) of modality B from the upper horizon. Acari (mostly oribatid, astigmatic, and mesostigmaticmites) represented $449(27 \%)$ individuals of the sample, not identified individuals made up to 349 (21\%). Even though macro fauna of the sample does not represent a percent, it is important to mention, that there here were found three coleopteran representatives and three digger wasps. As stated in "Fundamentals of soil ecology" (Coleman, 2004), these wasps construct nests in the soil, where they lay eggs in the prey (another insect or a spider).

Sample of the upper horizon of the modality $\mathrm{T}$ consisted of 87 (48\%) of acari individuals (mostly oribatid), only $9(5 \%)$ collembolas, $4(2 \%)$ enchytraeidae and $2(1 \%)$ micro arthropods (diplura).

As for horizon $20-40 \mathrm{~cm}$ (Figure 7), the most individuals of the soil fauna were found in the sample of modality B. It consisted generally from collembolas (45\%, 181 individuals)) and acari (25\% (105 individuals)). In the modality A there were almost equally acari and collembolas ((110) $30 \%$ and (109) 29\% accordingly). Micro arthropods constituted 5\% of the population, mostly by dilpurajapygidae. In the horizon $20-40 \mathrm{~cm}$ of modality A were found 13 coleopteras $(3 \%$ of the sample). Total quantity of individuals, found in the sample $\mathrm{T}$ was times less than in modalities $\mathrm{A}$ and B. From the recognised, acari represented 52\% (25 individuals) of the sample, collembollas $15 \%$ ( 7 individuals). In modality B were found two digger wasps and one was extracted from modality $\mathrm{T}$. In this horizon of modality B was also found presumably arthropod pseudoscorpions. They usually live in the deep subterranean medium, always in the most humid places.

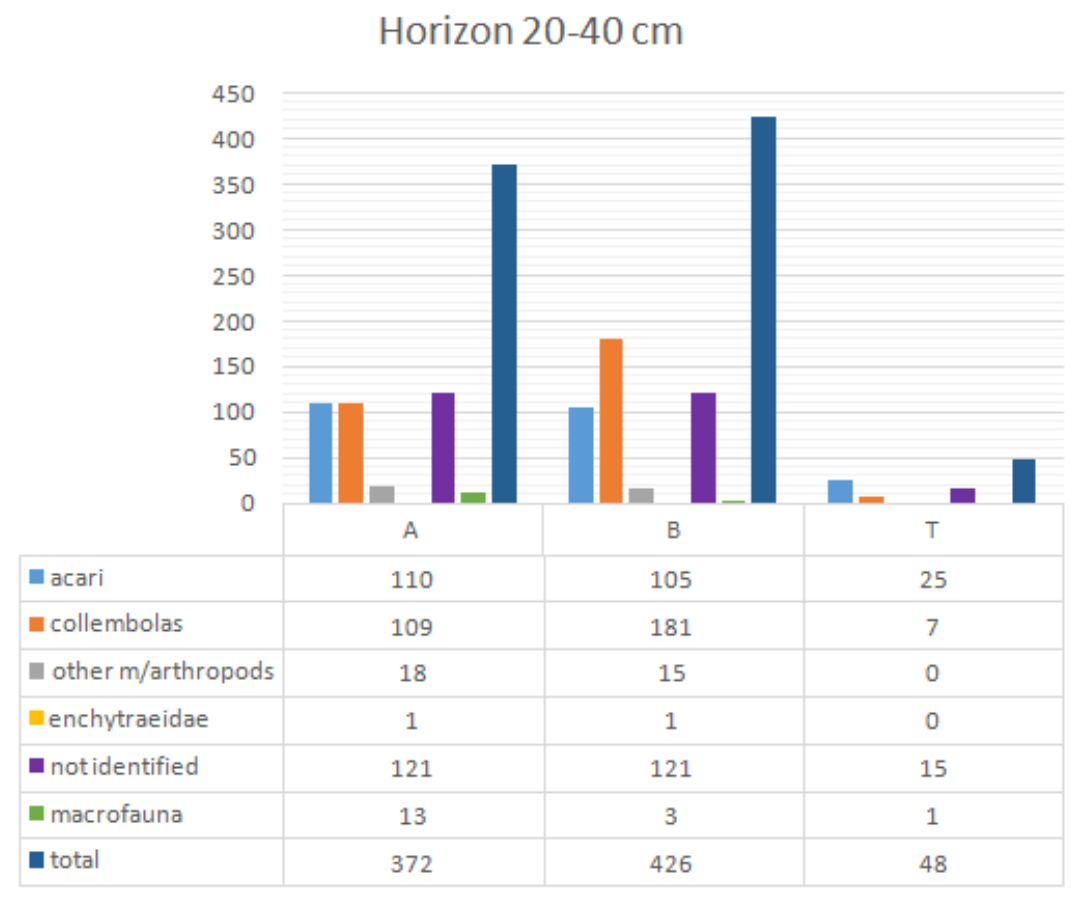

Figure7: Population rates between modalities (March) 
Samples from the upper horizon (Figure8), undertaken on the $25^{\text {th }}$ of April, demonstrated an increase in the quantity of individuals in all the modalities: up to 100 individuals in $\mathrm{A}$ and $\mathrm{B}$; rise in modality $\mathrm{T}$ was twice less, up to 46 individuals.

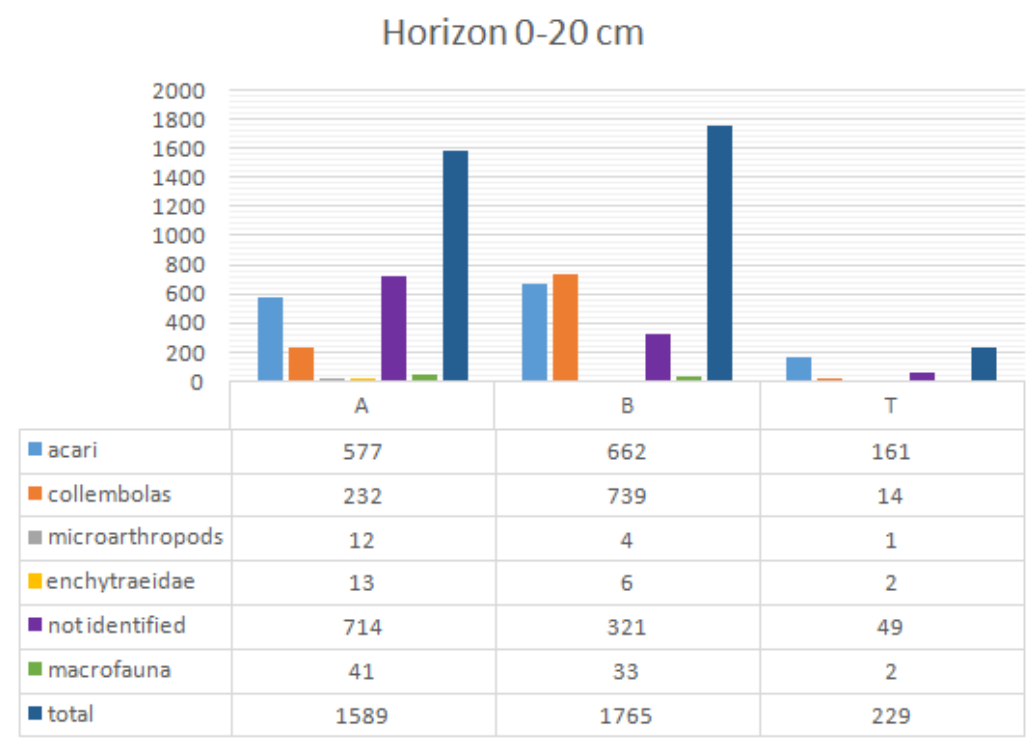

Figure8: Population rates between modalities (April)

Sample of the modality A consisted of 36\% of acari, mostly astigmatid and oribatid (248 and 91 individuals accordingly, out of total quantity of acari 577). Collembolas represented 323 individuals (15\% of the sample), 714 (45\%) individuals were not recognised because of their small size in undeveloped juvenile stage. Macro fauna constituted $2 \%$ of the sample within eighteen ants, fourteen coleoptera and nine larvas (presumably of coleoptera). According to Coleman (2004): Ants have a large impact on their ecosystems, they are "ecosystem engineers", moving large volumes of soil as much as earthworms do. Ants are major predators of small invertebrates (including oribatid mites). In this modality were observed five representatives of the insect, presumably Grylloidea super family, which is very poorly studied.

The $38 \%$ of the upper horizon of modality B consisted from acari (662 individuals), mostly oribatida, but also mesostigmatid, prostigmatid and astigmatid. Collembolas represented $42 \%$ of the modality (739 individuals), mostly arthroplenoid. Among other arthropods there were found two diplura japygidae. Macrofauna contained eight larvas, two dipteras, nineteen ants, two coleopteras, one centipeda and one digger-wasp.

The upper horizon of modality $\mathrm{T}$ contained $70 \%$ of acari (161 individuals). Collembolas represent 14 individuals $(6 \%)$, there also were found two enchytraeidae $(1 \%)$ and one diplura japygidae $(1 \%)$. Macrofauna (1\%) was present by one wasp and one ant.

\begin{tabular}{|l|r|r|}
\hline \multicolumn{1}{|c|}{ Horizon $20-40 \mathrm{~cm}$} \\
\hline
\end{tabular}

Figure9: Population rates, horizon 20-40cm (April) 
It is obvious from the graph (Figure9), that between samples of the nether horizon, most individuals were found in modality B (229), followed by A (176). Several times less in quantity of individuals was modality $\mathrm{T}$.

Modality A mostly consisted from acari (577 individuals) and collembolas (232 individuals) (38\% and $32 \%$, accordingly). In the majority, acari were represented by oribatida and some mesostigmatic mites. Mesostigmatic mites, as mentioned by (Larochelle, 1993), are not able to fragment organic residues. They usually feed on fungi or predators on micro- and mesofauna. Among the other micro arthropods, there were six diplurajapygidae, which are also mycophagous and predators on small arthropods (collembolans, nematodes, and enchytraeids). Macro fauna was present in the sample by one coleopteran and one centipede.

$44 \%$ of the modality B (662 individuals), nether horizon, were acari (mostly oribatida), 36\% contained collembolas (739 individuals), arthroplenoid in majority. There were found six diplura japygidae, and two enchytraeidae, one larva.

Among 13 individuals, found in the horizon $20-40 \mathrm{~cm}$ of the modality $\mathrm{T}$, there were five acari (13\%), two diplura japygidae, five not identified. There was identified, however, found one individual, that was not observed before: Typhlosorius torressalai (type species of the genusTyphlosorius). It is a micropredator of small soil intvertebrates.

\subsection{Humidity of the Soil}

Humidity was compared: 1) Between modalities generally, as sums of the whole season, within horizons 2) At each sampling taken, within horizons

Sums of the season showed the significant difference between all modalities within horizon $0-20 \mathrm{~cm}$. Highest \%humidity was observed in modality B, lowest in modality T. Within horizon $20-40 \mathrm{~cm}$ we observe the same tendency. There is significant difference between all modalities. Soil of modality B has the highest $\%$ of humidity among all modalities of observed period.

Examining in details horizon $0-20 \mathrm{~cm}$, first sampling demonstrated that modality B showed the highest $\%$ humidity (mean 10.83\%), however it was not significantly different from modality A. There was significant difference between these two modalities and modality T. Second sampling demonstrated significant difference between modalities. Modality B again had the highest \% humidity. Third sampling demonstrated significant difference between modalities $\mathrm{B}$ and $\mathrm{T}$ (mean values $7.17 \%$ and $4.67 \%$ accordingly). Soil humidity of modality a horizon $0-20$ was at $5.95 \%$ and has not differed statistically not from B neither from $\mathrm{T}$.

Analysing more precisely horizon $20-40 \mathrm{~cm}$ of studied modalities, in the first and third samplings, difference between modalities was not observed. Second sampling demonstrated significant difference between modality A and others that was expressed in the lowest \% humidity (mean 10.56\%). There was no significant difference between B and $\mathrm{T}$ with 13.25 and 12.9 relatively. We can assume that cover crops, before they were mowed, consumed water from the deeper soil horizon and even five days of high atmospheric humidity did not compensate this loss.

\subsection{Leaf Water Potential}

Statistical test on data obtained from the analyses of predawn leaf water potential indicated difference through the season of this study. This difference was significant between modalities B and $\mathrm{T}$. between $\mathrm{A}$ and $\mathrm{B}, \mathrm{A}$ and $\mathrm{T}$ difference doesn't show to be significant. Best water state according to predawn leaf water potential showed modality B following by A and concluding by $\mathrm{T}$.

After statistical analyses of the stem water potential outputs of the season, significant difference between modalities was not determined.

Looking at each date separately, predawn leaf water potential of the $20^{\text {th }}$ of May, demonstrated significant difference between modality $\mathrm{T}$ and others. Mean value modality $\mathrm{A}$ was at the highest rate (0.39 Mpa following by Bwith $0.36 \mathrm{Mpa}$ and $\mathrm{T} 0.22 \mathrm{Mpa}$ ), that determines $\mathrm{T}$ into the group "low water stress" and B and T into "low to moderate water stress". 
Stem leaf water potential of the $20^{\text {th }}$ of May did not indicate statistically significant difference between modalities, with the values $0.7 \mathrm{Mpa}$ for modality A; 0.83Mpafor modality B and 0.79Mpafor modality T, they all appeared to be in the group "moderate to severe water stress".

Predawn leaf water potential of the $4^{\text {th }}$ June showed significant difference between modalities B and T. More stress showed modality T, but values of all modalities ( $0.66 \mathrm{Mpa}$ for A; $0.57 \mathrm{Mpa}$ for B and $0.76 \mathrm{Mpa}$ for T) were inside one classified group "moderate to severe water stress". Stem leaf water potential of the $4^{\text {th }}$ June didn't show significant difference between modalities. They were all in a group "low water stress" (0.82Mpafor A; 0.9Mpafor B and 0.75Mpafor T).

Predawn leaf water potential on the $21^{\text {st }}$ of June did not show statistical difference between modalities and they all belonged to the group "moderate to severe water stress" (0.69Mpa for A; 0.62Mpafor B and $0.72 \mathrm{Mpa}$ for T). Significant difference was observed between stem water potential of the modalities. Highest rate of the pressure showed modality T, least pressure was applied in modality B. Stem water potential of modalities $\mathrm{A}$ and $\mathrm{T}$ were in the same classified group "moderate to severe water stress" with $1.22 \mathrm{Mpa}$ and 1.26 Mpa accordingly. Modality B, with 1.03Mpa, appeared in the group "low to moderate water stress".

Predawn leaf water potential on the $8^{\text {th }}$ of July did not show statistical difference between modalities. Modality A showed $0.48 \mathrm{Mpa}, \mathrm{B} 0.44 \mathrm{Mpa}$ and $\mathrm{T} 0.48 \mathrm{Mpa}$; all these values correspond to "low to moderate water stress" group. Stem water potential demonstrated that modality B was significantly different from A and T. Stem water potential of modalities A and T were in the same classified group "moderate to severe water stress" with 1.20 Mpa and 1.21 Mpa accordingly. Modality B appeared in the group "low to moderate water stress" with $1.00 \mathrm{Mpa}$.

Predawn leaf water potential of the $26^{\text {th }}$ of July demonstrated significant difference between modalities. Pursuant to the values of pressure chamber, modalities A and B belonged to the group "moderate to severe water stress", with mean values $0.74 \mathrm{Mpa}$ and $0.76 \mathrm{Mpa}$ accordingly, while T, with its $1.03 \mathrm{Mpa}$ was in "severe water stress" group. All values of the stem water potential are determined as being in "severe water stress" group, with mean values 1.53 Mpa, 1.47 Mpa and 1.54 for modalities A, B and T relatively. Statistical test has not determined significant difference between modalities.

\section{COnClusions}

The important rise in OM was proved in modalities a (cover crop in the inter-row and RCW under the row) and B (covered with RCW). Cover crop proved its beneficial property in increase of OM, when modality A showed the highest \% in the last sampling. Generally, through the season, the highest percentage of OM demonstrated modality $\mathrm{B}$, the lowest modality $\mathrm{T}$.

The amount of nitrogen in the vine tissues did not appear to be low in modality $\mathrm{B}$, as it was expected. In the contrary, it was higher than in other modalities. It can be explained by its origin, as Angiosperms (plantain trees) contains more nitrogen and nutrients in its tissues. The lowest percentage demonstrated modality A. It probably means that even though the OM content was increased by addition of decayed beans, the vine did not have appropriate conditions to extract nitrogen from the soil. No effect achieved in the nitrogen contribution by beans can be also explained by some sort of stress (heat, absence of water), that diminished nitrogen fixation of these plants and its accessibility to the plant consequently.

Modality A also showed to be significantly the driest nether horizon of the second sampling. Presumably, cover crops, before they were mowed, consumed water from the deeper soil horizon. This might prove that cover crop under the conditions of hot and dry Mediterranean climate increases dryness of the soil.

On the other hand, according to predawn leaf water potential, which is more precise under the Mediterranean climate conditions, sever water stress in the veraison moment was observed only in modality $\mathrm{T}$. This means, that $\mathrm{CC}$ at this period did not create additional water stress, in the contrary, probably due to its presence in the inter-row, vine developed its roots into nether horizons for the water uptake. 
Nevertheless, stem $\Psi$ demonstrated significant difference between modalities in the end of June, when modality B appeared to be in the "low to moderate water stress" category, while A and T already had "moderate to severe water stress". Even though water state of the vines in modality B was better than in other modalities, predawn $\Psi$ at this moment was in the same category "moderate to severe water stress". This corresponds to the last stage of the flowering when demonstrated early stress might decelerate the indicated stage of the vine development.

Generally, soil of the modality B had the highest $\%$ of humidity among all modalities of observed period; T demonstrated the lowest, which proves positive effect of the RCW on the conservation of the soil moisture by preventing its evaporation.

As for the "biological soil fertility", it was present in abundance in modalities A and B, times more than in the conventional plot. Second sampling characterised by expansion not only on amount, but also variability of the individuals in these two modalities. Presence of important quantities of collembolan in modality B proves the presence of fresh $\mathrm{OM}$ in this modality, as these micro arthropods are selective to the habitat. The earthworms were found also only in this modality. Welldeveloped food chain in modalities A and B was observable: from high amount of microbial respiration and presence of the fungi till ants, digger-wasps and coleopterans. During the third sampling in the structure of the modality B were found soil aggregates (Figure 10). The presence of the soil aggregates the covered with RCW modality and the appearance of this modality in the "moderate to severe" water stress group, comparing to the soil under cultivation, corresponds to the expected aim of this study-the improvement of the soil quality and its consequence on the better water state of the vine plant.

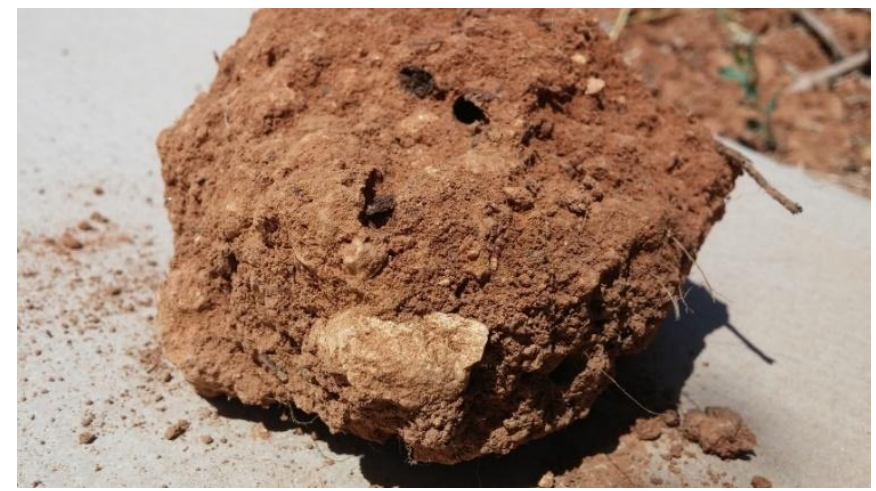

Figure10: Soil aggregate, modality $B$

\section{REFERENCES}

[1] Aira, M., Monroy, F., Dominguez, J. (2007b). Earthworms strongly modify microbial biomass and activity triggering enzymatic activities during vermi composting independently of the application rates of pig shurry. Sci. Total Environ., 385, 252-261.

[2] Aira, M., Sampedro, L., Monroy, F., Dominguez, J. (2008). Detritivorous earthworms directly modify the structure, thus altering the functioning of a micro decomposer food web. Soil Biol. Biochem., 40, 25112515.

[3] Anderson, S.R. (1992). Morphous Morphology. Cambridge University Press, UK

[4] Bodega Baron d'Alba (2016). Retrieved from Bodega Baron d'Alba: http://www.barondalba.com/

[5] Climate-Data Organization (2016, August 12). Climate: Castellon de la Plana. Retrieved from

[6] climate-data.org: http://en.climate-data.org/location/2097/

[7] Choneâ, X. (2001). Stem Water Potential is a Sensitive Indicator. Retrieved from http://aob.oxfordjournals.org/content/87/4/477.full.pdf

[8] Coleman, D. C. (2004). Chapter 4 the Soil Fauna. In David C. Coleman, Fundamentals of Soil Ecology.

[9] European Commission, E. E. (2016). About Climate-Adapt. Retrieved from CLIMATE-ADAPT European Climate Adaptation Platform: http://climate-adapt.eea.europa.eu/about

[10] Fraga, H. J., Malheiro, A.C., Moutinho-Pereira, J. (2013). Future scenarios for viticultural zoning in Europe: Ensemble of projections and uncertainties. Int. J. Biometeorol., 57 (6), 909-925.

[11] Fraga, H. J. (2014). Viticultural zoning in Europe: Climate scenarios and adaptation measures. Tese de Doutoramento. UTAD, Vila Real, Portugal. 
Study of Grapevine Water State Improvement by Enhancing Quality of the Soil in the Vineyards of Castellon Region (Spain)

[12] Geeson, N.A., Brandt, C.J., Thornes, S.B. (2002). Mediterranean Desertification: A Mosaic of Processes and Responses. John Wiley \& Sons Ltd. Chichester, England.

[13] Institute Français de la Vigne et du Vin. (2016). Retrieved from http://www.vignevinsudouest.com/services-professionnels/methode-analyse/mesure-potentiel-hydrique-foliaire-tige.php

[14] Jones, G. V. (2007). Climate Change: Observations, Projections, and General Implications for Viticulture and Wine Production. Ashland, Oregon, United States of America.

[15] Lindemann, W.C., and Glover, C.R. (2003). Nitrogen fixation by legumes. New Mexico State University. Cooperative Extension service Guide A-129 (Las Cruces).

[16] Lindemann, W.C., and Glover, C.R. (2008). Nitrogen fixation by legumes. Cooperative Extension service Guide A-129. New Mexico State University, USA.

[17] Larochelle, L.F.P. (1993). Rôle de la mésofaune dans la dynamique de transformation de la matière ligneuse appliquée au sol. Quebec, Canada.

[18] Meteoblue (2016). Climate Users. Retrieved from meteoblue.com: https://www.meteoblue.com/en/weather/forecast/modelclimate/useras_spain_3107147

[19] Monroy, F., Aira, M., Dominguez, J. (2009). Reduction of total coliform numbers during vermi composting is caused by short-term direct effects of earthworms on microorganisms and depends on the close of application of the pig shurry. Sci. Total Environ. 407, 5411-5416.

[20] Monroy, F., Aira, M., Dominguez, J. (2011). Epigeic earthworms increase soil arthropod populations during first steps of decomposition of organic matter. Pedobiología, 54, 93-99.

[21] Poupelin, M., Hotte, H., Cluzeau, D. (2016). Protocole «Prélèvement des Lombriciens ». Universdité de Rennes1, France. http://ecobiosoil.univ-rennes1.fr

[22] PNACC (2006). The Spanish National Climate Change Adaptation Plan. Madrid, Spain.

[23] Proffitt, T. (2012). Managing grapevine nutrition and vineyard soil health. Sustainable agriculture FACTSHEET no. 3. Perth Region Natural Resources Management in partnership with Wines of Western Australia.

[24] Proffitt, T. (2014). Assessing soil quality and interpreting soil test results. Sustainable agriculture FACTSHEET no. 3. Perth Region Natural Resources Management in partnership with Wines of Western Australia.

[25] Rochette, P.G.L., Hutchinson, G. (2005). Measurement of Soil Respiration in situ: Chamber Techniques. Publications from USDA-ARS/UNL. Faculty. 1379. University of Nebraska-Lincoln, USA.

[26] Sancho Civera, J. (2001). Prácticas de diagnóstico y fertilidad de suelos.SPUPV, Editorial de la Universidad Politécnica de Valencia, España.

[27] Soils (2016). Ministerio de Agricultura y Medio Ambiente. Madrid, España. Retrieved from hispagua.cedex.es: http://hispagua.cedex.es/en/datos/suelos

[28] Soriano Soto, D. (2001). Prácticas de Edafología y Climatología. SPUPV, Editorial de la Universidad Politecnica de Valencia (España).

[29] The Australian Wine Research Institute (2010). Viti notes (grape wine nutrition). Liming. AWRI. RTP 0034.

[30] Walkley A., Black I.A. (1934). An examination of the degtjareff method for determination soil organic matter and prepared modification of the chronic acid filtration method. Soil Sci., 34, 29-38.

[31] Winchester, N.N. (1999). Identification of Potential Monitored Elements and Sampling Protocols for Terrestrial Arthropods. Victoria, British Columbia, Canada.

Citation: L. Shkarupilo et al., " Study of Grapevine Water State Improvement by Enhancing Quality of the Soil in the Vineyards of Castellon Region (Spain) ", International Journal of Research Studies in Agricultural Sciences, vol. 3, no. 11, p. 1-17, 2017. http://dx.doi.org/10.20431/2454-6224.03011001

Copyright: (C) 2017 Authors. This is an open-access article distributed under the terms of the Creative Commons Attribution License, which permits unrestricted use, distribution, and reproduction in any medium, provided the original author and source are credited. 